\title{
Analisis Penentuan Lokasi Program Keluarga Harapan Dalam Menanggulangi Masalah Kekumuhan di Kota Tebing Tinggi, Sumatera Utara
}

\author{
Chairida Yunita Putri ${ }^{1 *}$, Sirojuzilam ${ }^{2}$, Rujiman ${ }^{3}$ \\ ${ }^{1,2,3}$ Perencanaan Wilayah Pedesaan, Sekolah PascaSarjana, Universitas Sumatera Utara
}

*Koresponden email: chairidayunitaputri@gmail.com

Diterima: 28 Februari 2020

Disetujui: 10 Maret 2020

\begin{abstract}
Slum is a general impression or picture of attitudes and low behavior seen from the standard of living and middle class income. Communities that live in slums economically are generally classified as poor and low-income groups, which are often the reason for the degradation of discipline and disorder in various social order. This study aims to investigate and determine the right location for Family Hope Program (PKH) implementation so program implementation can be more targeted and targeted and able to reduce and overcome the problem of slums in Tebing Tinggi City, North Sumatra province. The method used is to use spatial analysis with a Geographic Information System (GIS) and 5 indicators data from TNP2K. These indicators are combined and modeled spatially using 3 class locations namely Inaccurate, Less Accurate and Precisely Accurate. The results of spatial analysis and modeling are the location of Inaccurate (Tebing Tinggi Kota sub-district), Less Accurate (Padang Hilir and Padang Hulu sub-district) and Precisely Accurate (Bajenis and Rambutan sub-district). The resulting spatial model was validated with satellite photos from Google Earth and photos of field visits using triangulation validation techniques
\end{abstract}

Keywords: Slums, Poverty, Spatial Analysis, Spatial Modeling, Google Earth, Hope Family Program, GIS

\begin{abstract}
Abstrak
Kumuh dan kekumuhan merupakan kesan atau pandangan umum mengenai sikap dan prilaku rendah tampak dari standar hidup dan pendapatan kelas menengah dan menengah ke bawah. Masyarakat yang tinggal di kawasan permukiman kumuh secara ekonomi umumnya adalah golongan masyarakat miskin dan berpendapatan rendah, yang seringkali dijadikan alasan sebagai penyebab munculnya degradasi kedisiplinan dan ketidaktertiban di berbagai tatanan sosial masyarakat. Penelitian ini bertujuan menyelidiki dan menentukan lokasi yang tepat untuk pelaksanaan Program Keluarga Harapan (PKH) sehingga implementasi program dapat lebih terarah dan tepat sasaran dan mampu mengurangi serta menanggulangi masalah kekumuhan di Kota Tebing Tinggi, provinsi Sumatera Utara. Metode yang digunakan adalah dengan metode analisis spasial dengan Sistem Informasi Geografis (SIG) menggunakan data 5 indikator dari TNP2K. Indikator-indikator ini digabung dimodelkan secara spasial dengan menetapkan 3 kelas lokasi yaitu Tidak Tepat, Kurang Tepat dan Tepat Sasaran.Hasil analisis dan pemodelan spasial pada penelitian ini adalah lokasi Tidak Tepat sasaran (Kecamatan Tebing Tinggi Kota), Kurang Tepat (kecamatan Padang Hilir dan Padang Hulu) dan Tepat Sasaran (Kecamatan Bajenis dan Rambutan). Model spasial yang dihasilkan divalidasi dengan foto satelit dari GoogleEarth dan foto kunjungan lapangan dengan teknik validasi trianggulasi

Kata Kunci: Kekumuhan, Kemiskinan, Analisis Spasial, Pemodelan Spasial, Google Earth, Program Keluarga Harapan, SIG
\end{abstract}

\section{Pendahuluan}

Kumuh dan kekumuhan merupakan kesan atau pandangan umum mengenai sikap dan prilaku rendah tampak dari standar hidup dan pendapatan kelas menengah dan menengah ke bawah. Dapat pula diartikan bahwa kumuh dan kekumuhan adalah tanda atau stempel yang diberikan golongan atas yang mampu terhadap golongan bawah yang belum mampu. Kumuh bisa dilokasikan sebagai penyebab tapi dapat juga di masukkan sebagai akibat. Namun dimanapun berada, , kata kumuh dan kekumuhan terap cenddrung untuk hal yang negatif dan tidak baik ([1] dalam [2]). Pada bidang sosial budaya kemasyarakatan, masyarakat yang berlokasi di kawasan permukiman kumuh, perekonomiannya termasuk kelompok masyarakat miskin dan berpendapatan rendah, yang acapkali sebagai alasan ditenggarai 
terjadinya penurunan kedisiplinan dan ketidakteraturan serta ketidaktertiban dalam bermacam kondisi sosial masyarakat [3].

Kompleksnya kawasan kumuh dapat muncul bisa disebabkan beberapa hal, yaitu keadaan rumah yang tidak layak huni karena keadaan perekonomian masyarakat yang kurang baik, terutama masyarakat berpendapatan rendah. Ini menyebabkan masyarakat berpendapatan rendah tidak bisa mempunyai rumah yang layak huni. Level kepadatan bangunan dan perumahan yang tinggi pada permukiman kumuh memberikan informasi yaitu masyarakat tidak mampu 'membeli' tanah yang lebih baik untuk membangun rumah. Salah satu efek tingkat kepadatan bangunan dan perumahan yang tinggi ialah sarana dan prasarana dasar kawasan yang ada belum mampu merangkul seluruh permukiman [4].

Dalam rangka percepatan penanggulangan kemiskinan, sejak tahun 2007 Pemerintah Republik Indonesia telah mencanangkan dan melaksanakan Program Keluarga Harapan (PKH). Program yang sama telah pula dilakukan dan memberikan hasi yang cukup menggembirakan di beberapa Negara yang dikenal pula dengan nama Conditional Cash Transfers (CCT) atau bantuan tunai bersyarat. PKH bukan merupakan kesinambungan dari program Subsidi Langsung Tunai (SLT) yang dilaksanakan dalam upaya membantu rumah tangga miskin mempertahankan daya belinya di saat pemerintah melaksanakan penyesuaian harga Bahan Bakar Minyak (BBM). Tetapi PKH lebih ditujukan sebagai usaha dalam membangun sistem perlindungan sosial untuk masyarakat miskin. Dengan melihat pengalaman negaranegara berkembang lain, program ini bisa sangat berguna terutama untuk keluarga dengan level kemiskinan yang sangat buruk. PKH ini muncul sebagai terobosan dalam percepatan penanganan kemiskinan dan juga sekaligus untuk sarana dalam mengembangkan sistem jaminan sosial untuk masyarakat kelompok sangat miskin yang berhak memperoleh bantuan tunai bersyarat atau PKH [5].

Penelitian bertujuan menyelidiki dan menentukan lokasi yang tepat untuk pelaksanaan Program Keluarga Harapan (PKH) sehingga implementasi program dapat lebih terarah dan tepat sasaran dan mampu mengurangi serta menanggulangi masalah kekumuhan di Kota Tebing Tinggi, provinsi Sumatera Utara.

\section{Studi Literatur}

\section{Kemiskinan dan Permukiman Kumuh di Kota Besar}

Kemiskinan di daerah perkotaan mengakibatkan golongan masyarakat yang berpendapatan rendah mendapatkan nasibnya lebih jelek karena mereka bahkan tidak bisa dan tidak mampu untuk menempati rumah-rumah kumuh. Kenaikan kebutuhan bangunan serta perkembangan kawasan kumuh dan liar karena kemiskinan dalam kota akan semakin meningkat pesat. Jika ditinjau dari sisi tersebut maka kita pesimis dalam menyediakan sarana permukiman karena kondisi kemiskinan yang naik dan indikator ekonomi yang terus menurun tajam pada saat ini [6].

Kawasan permukiman kumuh adalah isu yang dialami oleh semua kota-kota besar di Indonesia dan kota-kota besar di negara berkembang lainnya. Studi mengenai kawasan kumuh (slum), secara umum meliputi tiga bagian, yaitu, pertama, keadaan fisiknya. Keadaan fisik dapat dilihat dari keadaan bangunan/rumahnya yang sangat rapat dengan nilai kualitas konstruksi yang rendah, jaringan jalan tidak baik, tidak berpola dan tidak diperkeras seperti jalan tanah yang becek saat hujan, kebersihan umum dan saluran drainase yang sering tidak berfungsi serta masalah sampah yang belum dikelola baik. Kedua, keadaan ekonomi budaya dan sosial masyarakat yang tinggal di kawasan tersebut. Keadaan sosial ekonomi penduduk yang tinggal di kawasan kumuh meliputi tingkat penghasilan yang rendah, aturan sosial yang longgar, sikap kemiskinan yang menghiasi kehidupannya yang nampak dari sikap dan aktifitas yang cenderung apatis dan mudah menyerah. Ketiga, efek oleh kedua keadaan diatas, keadaan tersebut sering juga menjadikan keadaan kesehatan menjadi buruk, sumber pencemaran, sumber tersebarnya penyakit dan aktifitas dan perilaku menyimpang, yang berefek pada keseluruhan kehidupannya [7].

Ref [8] dalam tesisnya mengemukakan bahwa permukiman di bantaran sungai adalah permukiman kumuh. Hal ini dikarenakan pertumbuhan penduduk yang meningkat dan tidak cukupnya lokasi yang memadai untuk lokasi perumahan. Faktor kemiskinan menjadi sebab bantaran sungai menjadi lokasi permukiman yang pada umumnya adalah kumuh. Ref [8] memberikan saran dalam penelitiannya: Pemerintah Kabupaten Serdang Bedagai harus segera memperbaiki keadaan fisik dan mengelola permukiman kumuh di Kecamatan Tanjung Beringin sebagai berikut: a. Normalisasi sungai agar kawasan permukiman lebih teratur dan ekosistem lingkungan lebih seimbang ; b. Menaikkan kualitas bangunan tidak layak huni (RTLH) untuk masyarakat berpendapatan rendah (MBR) dan c. Memperbaiki dan meningkatkan kualitas jalan yang rusak. Pemerintah Kabupaten Serdang Bedagai diharapkan sanggup menurunkan tingkat kawasan permukiman kumuh yang ada di Kecamatan Tanjung Beringin dengan 
memperbaiki dan menata keadaan fisik dan memperbaiki keadaan bangunan di kawasan kumuh dan Pemerintah Kabupaten Serdang Bedagai harus segera menyiapkan master plan dalam menangani masalah kawasan kumuh secara menyeluruh dengan ikut menyertakan dinas dan instansi yang berkepentinagn dan terkait, yaiut pihak swasta dan masyarakat dengan pendekatan model konsolidasi lahan (Land Consolidation) dan pendekatan model rencana program Pembenahan kampung (KIP) [8].

\section{Penanggulangan Kemiskinan dan Kekumuhan Melalui Perencanaan Spasial Perkotaan}

Persoalan kemiskinan memicu hal seperti tampilnya kawasan permukiman kumuh yang diakibatkan oleh sumberdaya di kota, tidak dapat melayani kebutuhan seluruh masyarakat kota. Penyebab utama masalah kekumuhan di kota adalah dari kemiskinan, yang dikarenakan kemiskinan penduduknya dan lumpuhnya pemerintah kota dalam mempersiapkan layanan yang bauk dan memadai kepada seluruh penduduknya.

Informasi kemiskinan dengan basis spasial dan karakteristik kemiskinan spasial bisa menolong dan sangat dibutuhkan. Sehingga, disarankan bagi pemangku kepentingan, baik dari pihak pemerintah maupun non pemerintah agar mengambil beberapa tindakan, yaitu :1. Memupuk kesadaran bagaimana informasi kemiskinan berbasis spasial memegang peranan penting dan karakteristik kemiskinan spasial adalah basis pertimbangan baik dalam membangun rencana induk perkotaan ataupun dalam membangun rencana program penanggulangan kemiskinan dan 2. Membuat sistem proteksi sosial dan penyelesaian masalah kemiskinan yang sensitif atas kebutuhan dan kondisi kehidupat golongan miskin dan kerentanan yang di hadapi oleh golongan ini sesuai konteks basis spasialnya.

Secara teknis, memasukkan situasi kemiskinan dalam rencana wilayah/spasial perkotaan bisa dilakukan dengan berbagai sistem sebagai berikut: 1. Menyatukan data-data seputar kemiskinan bersama dengan informasi dengan basis spasial, seperti contoh, bisa dilakukan dengan aplikasi / software GIS ke dalam format peta interaktif maupun peta sosial. 2. Menjalin kemitraan dengan kelompok diluar pemerintah atau swasta maupun lembaga donor dalam berinovasi [9].

\section{Metode Penelitian}

Tempat atau lokasi penelitian dilaksanakan di wilayah administratif Kota Tebing Tinggi, Provinsi Sumatera Utara, dimana jenis penelitian ini adalah penelitian deskriptif kuantitatif [10] dengan menggunakan data primer dan sekunder. Data primer adalah data yang didapat langsung tanpa perantara dari pihak pertama atau langsung dari pengumpul data. Data sekunder merupakan kebalikan dari data primer yaitu data didapat dan digunakan oleh kelompok yang bukan pengelolanya [11]. Data primer yang dipakai merupakan data kunjungan lapangan berupa foto kunjungan lapangan. Data sekunder yang dipakai dalam riset ini adalah dari Tim Nasional Percepatan Penanggulangan Kemiskinan (TNP2K), Badan Pusat Stastistik (BPS) Kota Tebing Tinggi dan data spasial dari Badan Informasi Geospasial (BIG).

\section{Penentuan indikator kemiskinan}

Pada latar belakang dan tinjauan pustaka disebutkan bahwa kemiskinan adalah salah satu aspek utama pencetus kawasan kumuh. Tim Nasional Percepatan Penanggulangan Kemiskinan (TNP2K) mengumpulkan data dan menetapkan 16 indikator kemiskinan [12]. Dalam penelitian ini, peneliti memakai 5 indikator dalam menentukan lokasi pelaksanaan program PKH yang paling tepat. Indikator yang dipakai sebagai berikut: status kesejahteraan, kepala rumah tangga perempuan, pendidikan, kecacatan dan penyakit kronis.

\section{Analisis dan Pemodelan spasial indikator dengan metode intersect.}

Metode analisis data yang digunakan di penelitian ini merupakan metode/pendekatan analisis spasial dengan memanfaatkan teknologi Sistem Informasi Geografis (SIG) [13]. Kelima indikator akan dibuat analisis spasial sebaran masing-masing indikator dengan membaginya menjadi tiga kelas nilai. Kelima analisis spasial indikator ini akan digabung dengan metode geoprocessing intersect menjadi satu. Hasil penggabungan ini kemudian dibuat pemodelan spasial dengan membagi kelas menjadi tiga kelas yaitu Tidak Tepat, Kurang Tepat dan Tepat Sasaran. Nilai interval dalam kelas ini dilakukan dengan persamaan 1 sebagai berikut [14], [15], [16] :

$$
i=r / c
$$

dimana:

$$
\begin{array}{ll}
\mathrm{i} & =\text { Interval nilai. } \\
\mathrm{r} & =\text { Jarak pengukuran (nilai tertinggi }- \text { nilai terendah) } \\
\mathrm{c} & =\text { Kelas yang diminta/ditentukan. }
\end{array}
$$




\section{Validasi Model spasial}

Validasi adalah suatu aksi pembuktian, dimana validasi adalah suatu kegiatan "dokumentasi". Cara atau pendekatan pembuktian harus dengan "cara yang cocok", artinya proses pembuktian tersebut harus melalui aturan yang baku. "Obyek" pembuktian adalah setiap material, proses, prosedur, aktifitas, sistem, peralatan yang dipakai dalam produksi dan pengawasan mutu. Sasaran dari kegiatan validasi ini menyatakan yaitu seluruh entitas pengujian akan diharapkan mencapai keluaran yang dituju secara berkesinambungan (konsisten) [17].

Metode atau teknik validasi yang dipakai adalah metode trianggulasi. Triangulasi adalah metode pemeriksaan autentikasi data yang memmakai sesuatu yang di luar data untuk keperluan pemeriksaan atau sebagai pembeda terhadap data itu [18].

Validasi dilakukan dengan menggunakan data sekunder dari GoogleEarth. GoogleEarth adalah produk pemetaan di jaringan internet atau web yang diluncurkan dan dikembangkan oleh Google. Validasi juga dilakukan melalui kunjungan lapangan dan mengambil beberapa foto lokasi. Foto lokasi diambil dengan smartphone Android sehingga foto ini memuat informasi koordinat. Informasi koordinat akan membantu dalam memasukkan (plotting) foto keatas foto satelit Google Earth

\section{Hasil dan Pembahasan \\ Gambaran Umum Kota Tebing Tinggi}

Kota Tebing Tinggi adalah satu dari tujuh kota administrative yang berlokasi di Provinsi Sumatera Utara, dengan jarak sekitar 78 kilometer dari Kota Medan. Kota Tebing Tinggi terletak pada lokasi koordinat $3^{\circ} 19^{\prime} 00^{\prime \prime}-3^{\circ} 21^{\prime} 00^{\prime \prime}$ Lintang Utara dan 98 $8^{\circ} 11^{\prime}-98^{\circ} 21^{\prime}$ Bujur Timur. Kota Tebing Tinggi berlokasi di tengah-tengah Kecamatan Tebing Tinggi, Kabupaten Serdang Bedagai yang berbatasan dengan PTPN III Rambutan di bagian Utara, berbatasan dengan PT. Socfindo Kebun Tanah Besih di bagian Timur, berbatasan dengan PTPN III Kebun Pabatu di bagian Selatan, dan berbatasan dengan PTPN III Kebun Gunung Pamela Bandar Bejambu di bagian Barat. Gambar 1 menampilkan peta administrasi Kota Tebing Tinggi [19].

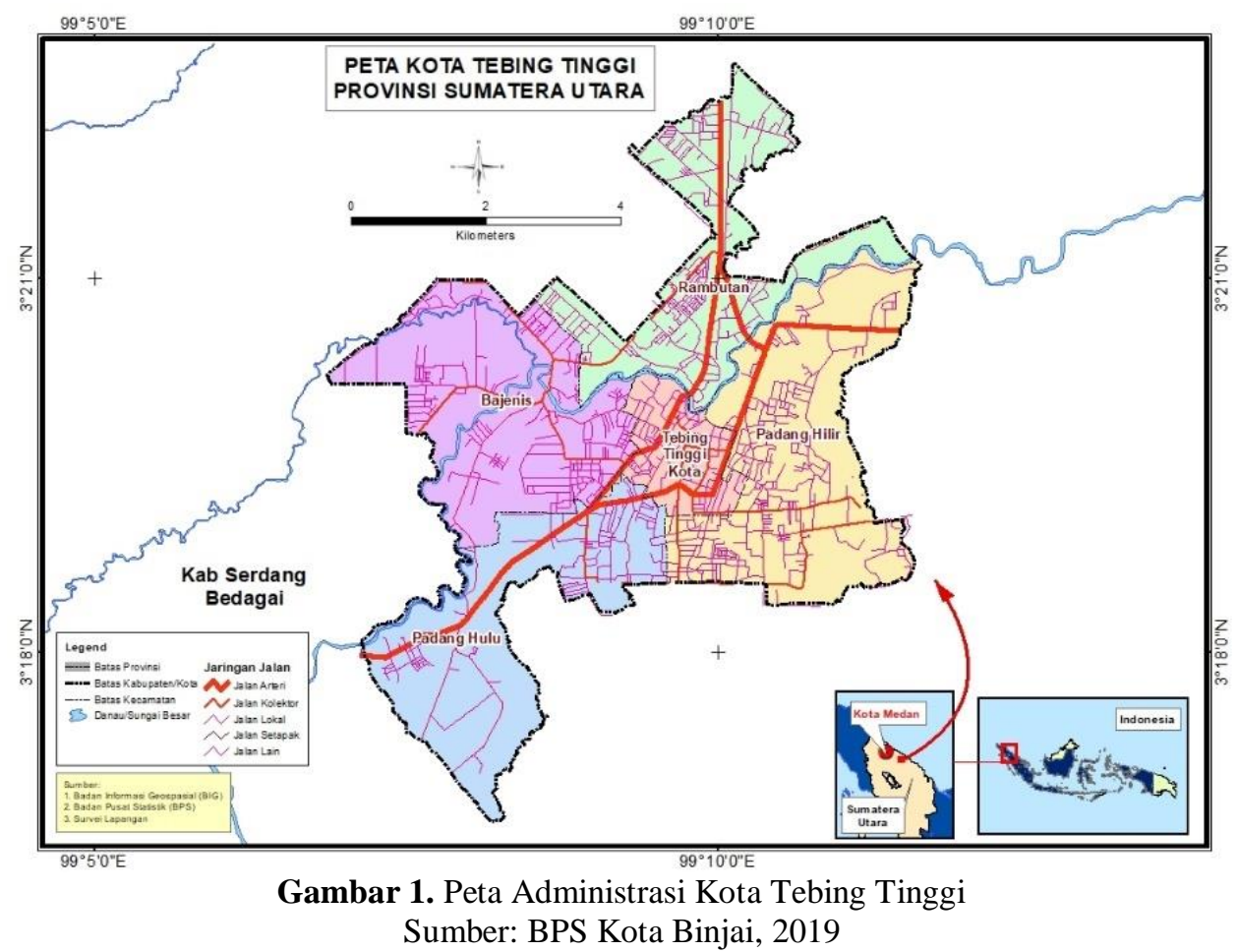

Sampai bulan Desember 2018, Kota Administratif Tebing Tinggi memiliki 5 kecamatan dan 35 kelurahan/kampung, dengan luas wilayah 38,438 km2. Kecamatan Padang Hilir adalah kecamatan dengan area terluas yaitu 11,441 km2 atau 29,76 persen dari luas total Kota Tebing Tinggi. Sebagian besar $(45,55 \%)$ lahan di Kota Tebing Tinggi merupakan lahan pertanian. Tabel 1 menampilkan daftar kecamatan-kecamatan di Kota Tebing Tinggi [19]. 
Tabel 1. Kecamatan di Kota Tebing Tinggi

\begin{tabular}{lcc}
\hline Kecamatan & Luas $(\mathrm{km} 2)$ & Persentase \\
\hline Padang Hulu & 8.511 & 22,14 \\
Tebing Tinggi Kota & 3.473 & 9,04 \\
Rambutan & 5.935 & 15,44 \\
Bajenis & 9.078 & 23,62 \\
Padang Hilir & 11.441 & 29,76 \\
\hline \multicolumn{2}{c}{ Sumber: Kota Tebing Tinggi Dalam Angka, 2019 }
\end{tabular}

\section{Indikator Penelitian}

Tabel 2 menampilkan data individu dengan kondisi kesejahteraan sampai dengan 10\% terendah di Indonesia. Data ini berasal dari TNP2K. Kecamatan Bajenis adalah kecamatan dengan tingkat kesejahteraan sampai $10 \%$ tertinggi dengan angka 5.542 orang atau $28 \%$.

Tabel 2. Individu dengan kondisi kesejahteraan sampai dengan 10\% terendah di Indonesia

\begin{tabular}{lcc} 
Kecamatan & Kesejahteraan sampai 10\% & Persentase \\
\hline Padang Hulu & 3.414 & 17 \\
Tebing Tinggi Kota & 2.566 & 13 \\
Rambutan & 4.947 & 25 \\
Bajenis & 5.542 & 28 \\
Padang Hilir & 3.619 & 18 \\
\hline Total & 20.088 & 100 \\
\hline
\end{tabular}

Tabel 3 menampilkan data kepala rumah tangga perempuan dengan status kesejahteraan $40 \%$ terendah. Dari Tabel 3, Kecamatan Rambutan adalah kecamatan dengan jumlah kepala rumah tangga tertinggi yaitu 516 orang atau $23 \%$.

Tabel 3. Kepala Rumah Tangga Perempuan dengan status kesejahteraan $40 \%$ terendah

\begin{tabular}{lcc}
\hline Kecamatan & Kepala Rumah Tangga Wanita & Persentase \\
\hline Padang Hulu & 440 & 20 \\
Tebing Tinggi Kota & 356 & 16 \\
Rambutan & 516 & 23 \\
Bajenis & 471 & 21 \\
Padang Hilir & 467 & 21 \\
Total & 2.250 & 100 \\
\hline
\end{tabular}

Sumber: TNP2K, 2015

Tabel 4 menampilkan data anak yang tidak bersekolah dengan status kesejahteraan $40 \%$ terendah di Kota Tebing Tinggi. Kecamatan Bajenis adalah kecamatan dengan jumlah anak yang tidak bersekolah terbanyak yaitu 3.366 orang anak atau $26 \%$

Tabel 4. Data anak yang tidak bersekolah

\begin{tabular}{lcc}
\hline Kecamatan & Anak tidak bersekolah & Persentase \\
\hline Padang Hulu & 2062 & 16 \\
Tebing Tinggi Kota & 1671 & 13 \\
Rambutan & 3166 & 24 \\
Bajenis & 3366 & 26 \\
Padang Hilir & 2845 & 22 \\
\hline Total & 13.110 & 100 \\
\hline
\end{tabular}


Tabel 5 menampilkan data penduduk yang mempunyai penyakit kronis dengan status kesejahteraan $40 \%$ terendah di Kota Tebing Tinggi. Kecamatan Padang Hulu adalah kecamatan dengan jumlah penduduk penderita penyakit kronis yaitu 5015 orang atau $26 \%$.

Tabel 5. Penduduk penderita penyakit kronis

\begin{tabular}{lcc}
\hline Kecamatan & $\begin{array}{c}\text { Penderita } \\
\text { Penyakit Kronis }\end{array}$ & Persentase \\
\hline Padang Hulu & 515 & 26 \\
Tebing Tinggi Kota & 225 & 12 \\
Rambutan & 387 & 20 \\
Bajenis & 496 & 25 \\
Padang Hilir & 329 & 17 \\
Total & 1.952 & 100 \\
\hline
\end{tabular}

Sumber: TNP2K, 2015

Tabel 6 menampilkan data penduduk dengan penyakit kronis dengan status kesejahteraan $40 \%$ terendah di Kota Tebing Tinggi.

Tabel 6. Penduduk penderita cacat

\begin{tabular}{lcc}
\hline Kecamatan & Penderita cacat & Persentase \\
\hline Padang Hulu & 197 & 26 \\
Tebing Tinggi Kota & 110 & 15 \\
Rambutan & 171 & 23 \\
Bajenis & 164 & 22 \\
Padang Hilir & 110 & 15 \\
Total & 752 & 100 \\
\hline
\end{tabular}

Sumber: TNP2K, 2015

\section{Analisis Spasial Indikator TNP2K}

Dari data masing-masing indikator TNP2K diatas, kita terjemahkan dengan analisis spasial. Analisis spasial dapat membantu dalam melihat secara visual sebaran atau distribusi masing-masing indikator.

Gambar 2 menampilkan analisis spasial distribusi individu dengan kondisi kesejahteraan sampai dengan $10 \%$ terendah di Indonesia. Gambar ini memberikan informasi bahwa kecamatan Bajenis dan Rambutan adalah 2 kecamatan dengan individu berkondisi kesejahteraan sampai dengan $10 \%$ terendah di Kota Tebing Tinggi dengan membagi analisis menjadi tiga kelas. 


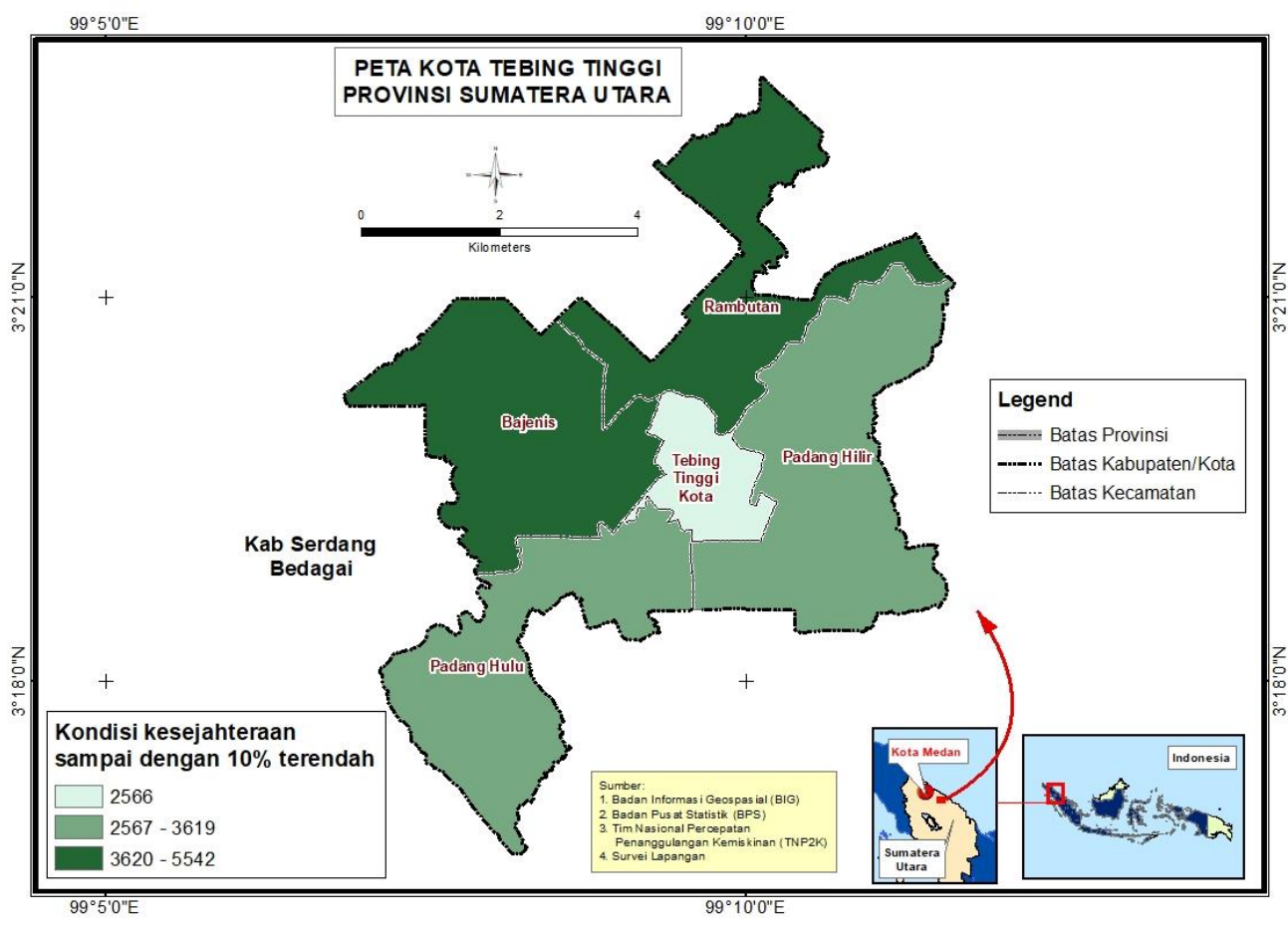

Gambar 2. Analisis spasial indikator individu dengan kondisi kesejahteraan sampai $10 \%$ terendah di Indonesia Sumber: Olah data, TNP2K, 2015

Gambar 3 menampilkan analisis spasial sebaran kepala rumah tangga perempuan di Kota Tebing Tinggi. Gambar ini memberikan informasi bahwa kecamatan Rambutan adalah kecamatan dengan jumlah kepala rumah tangga perempuan terbanyak di Kota Tebing Tinggi dengan membagi analisis menjadi 3 (tiga) kelas.



Gambar 3. Analisis spasial indikator kepala rumah tangga perempuan Sumber: Olah data, TNP2K, 2015 
Gambar 4 menampilkan analisis spasial sebaran anak tidak bersekolah di Kota Tebing Tinggi. Gambar ini memberikan informasi bahwa kecamatan Bajenis dan Rambutan adalah kecamatan dengan jumlah anak tidak sekolah paling banyak di Kota Tebing Tinggi. Analisis membagi kelas menjadi 3 (tiga) kelas.

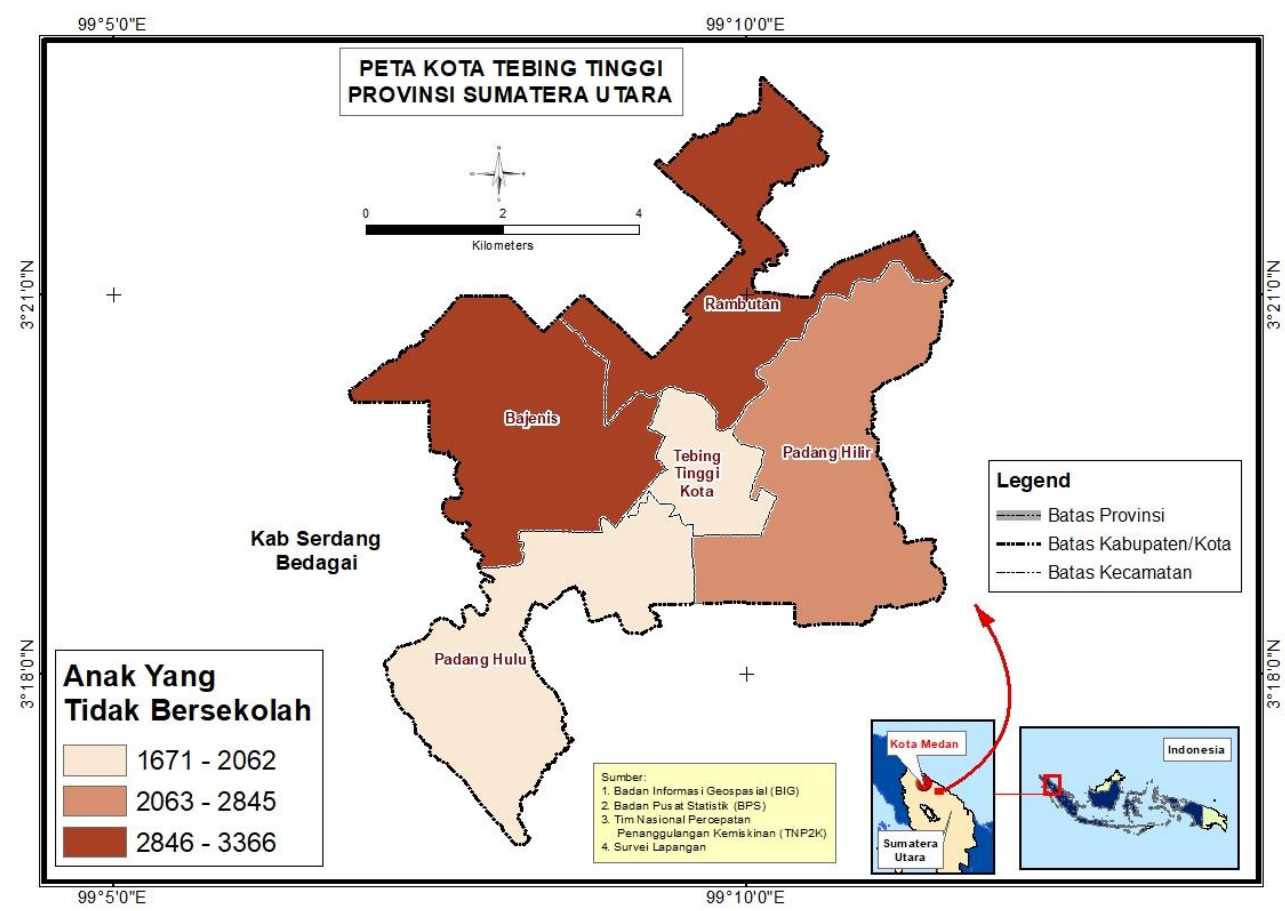

Gambar 4. Analisis spasial sebaran anak tidak sekolah Sumber: Olah data, TNP2K, 2015

Gambar 5 menampilkan analisis spasial sebaran penduduk dengan penyakit kronis di Kota Tebing Tinggi. Gambar tersebut memberikan informasi bahwa kecamatan Bajenis dan Padang Hulu adalah kecamatan dengan penduduk dengan penyakit kronis terbanyak di Kota Tebing Tinggi.

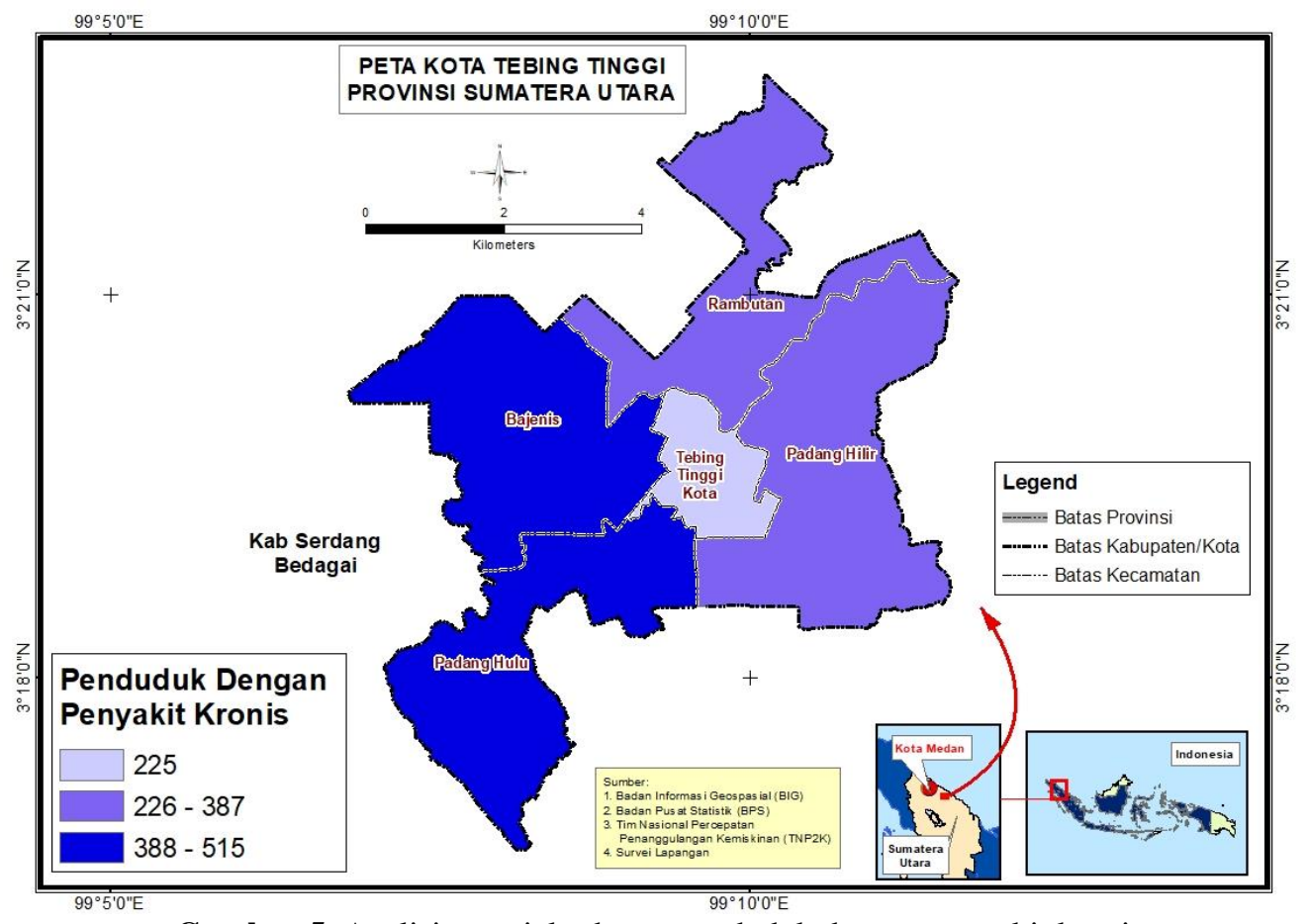

Gambar 5. Analisis spasial sebaran penduduk dengan penyakit kronis

Sumber: Olah data, TNP2K, 2015 
Gambar 6 menampilkan analisis spasial sebaran penduduk penyandang cacat di Kota Tebing Tinggi. Gambar ini memberikan informasi yaitu kecamatan Padang Hulu adalah kecamatan dengan angka penyandang cacat paling banyak di Kota Tebing Tinggi.

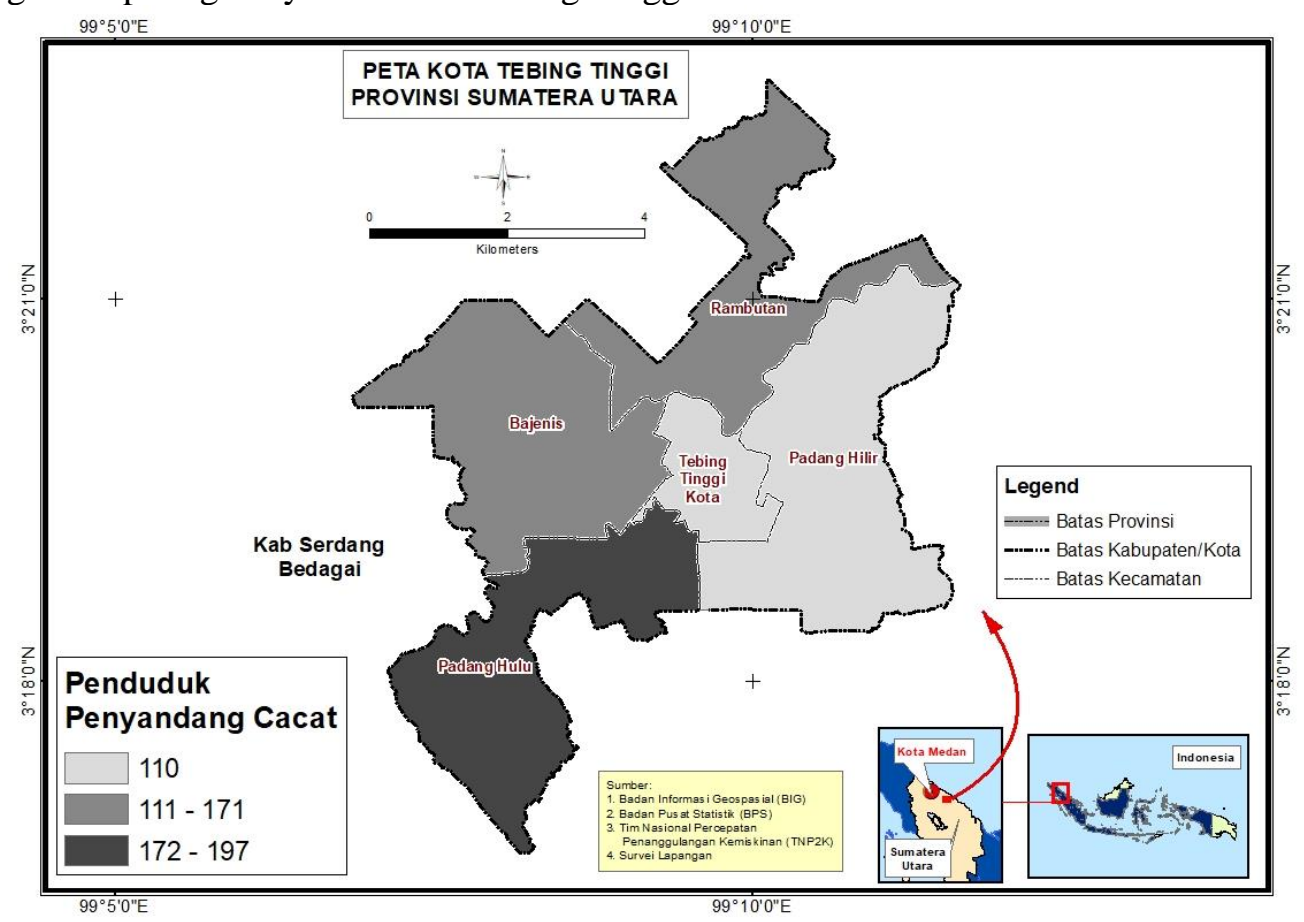

Gambar 6. Analisis spasial sebaran penduduk penyandang cacat di Kota Tebing Tinggi

Sumber: Olah data, TNP2K, 2015

\section{Pemodelan Spasial Menentukan Lokasi Pelaksanaan PKH}

Pemodelan spasial dapat menjadi alat pengambilan keputusan untuk menentukan lokasi yang paling tepat dalam mengimplementasi suatu program. Gambar 7 menampilkan pemodelan spasial dan pembagian 3 (tiga) kelas yaitu lokasi tepat sasaran, kurang tepat dan tidak tepat dalam mengimplementasikan PKH

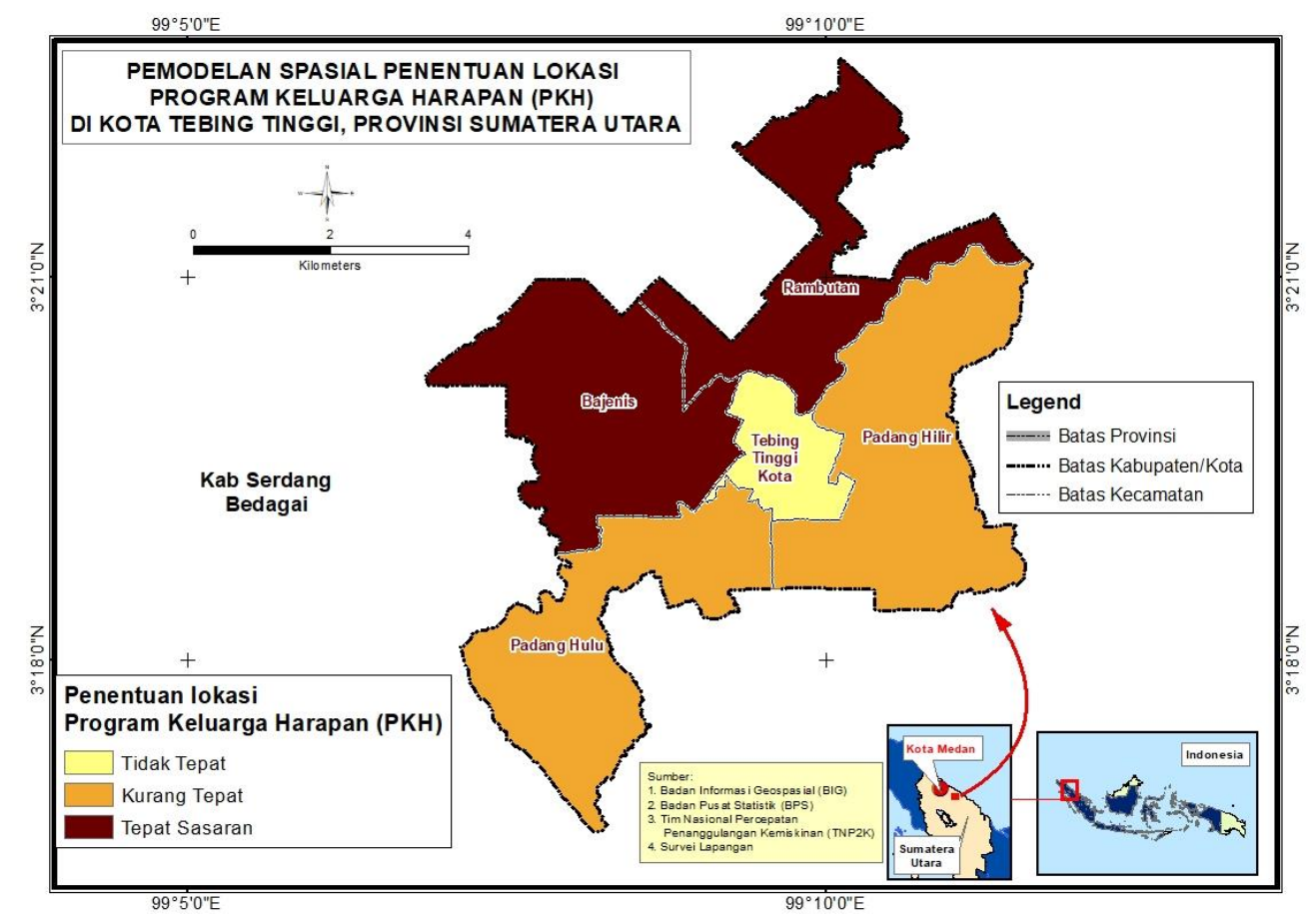

Gambar 7. Pemodelan spasial penentuan lokasi PKH di Kota Tebing Tinggi, Sumatera Utara. Sumber: Olah data, TNP2K, 2015 
Berdasarkan pada model spasial pada Gambar 7, memberikan informasi bahwa kecamatan Bajenis dan Kecamatan Rambutan adalah lokasi yang paling tepat sasaran dalam implementasi PKH.

\section{Validasi Model Spasial}

Gambar 8 menampilkan analisis spasial sebagai validasi model spasial penentuan lokasi yang telah dibuat. Analisis spasial pada Gambar 8 disertai dengan foto lokasi pemukiman kumuh. Foto lokasi ini menjadi validasi model spasial sebagai bukti bahwa model spasial penentuan lokasi telah valid/benar. Beberapa juga menampilkan lokasi di bantaran sungai Padang, Kota Tebing Tinggi. Ini sesuai dengan tesis [8] yang mengemukakan hal kekumuhan dikawasan bantaran sungai [8].

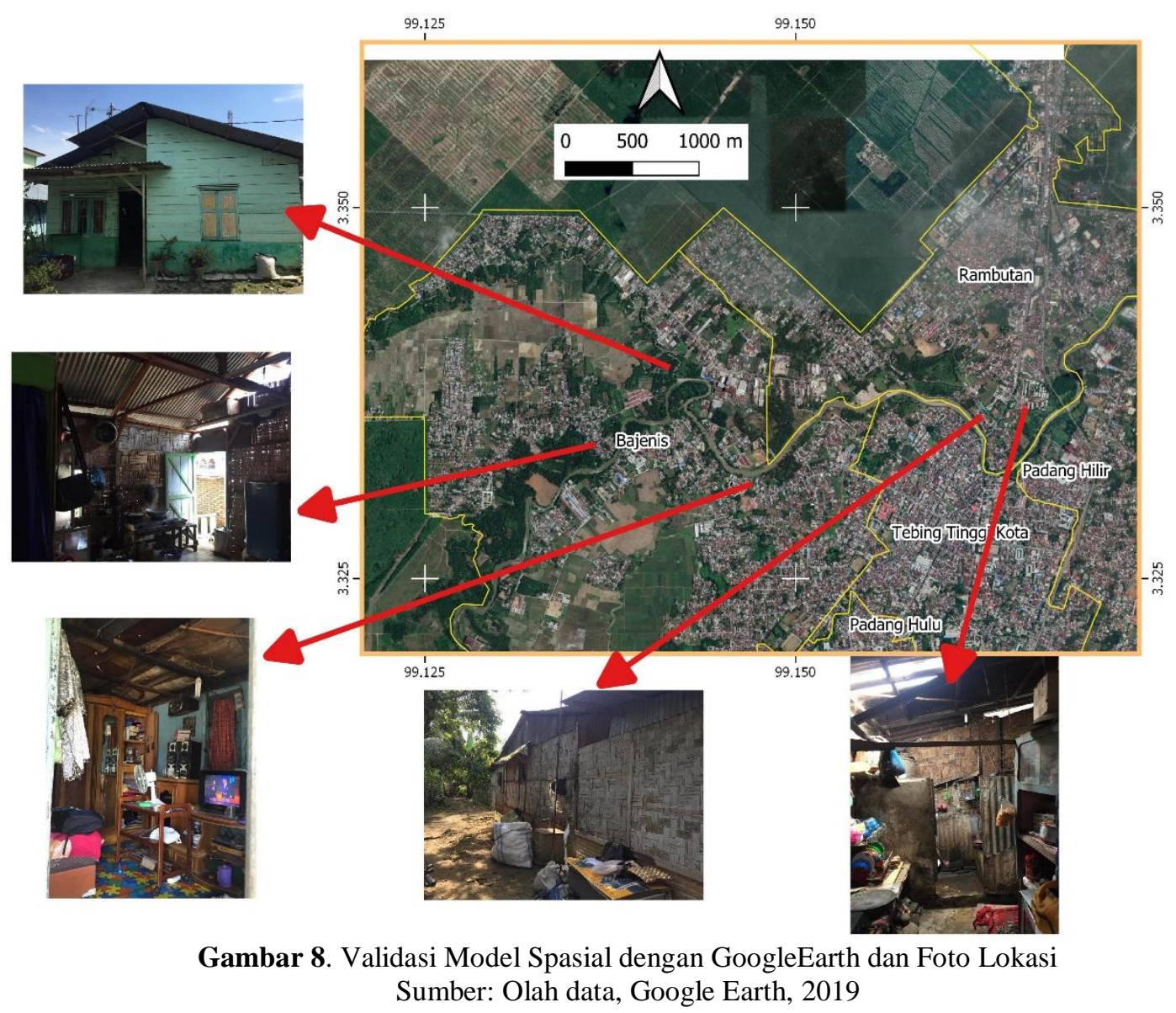

\section{Kesimpulan dan Saran Kesimpulan}

Penelitian mempunyai tujuan menyelidiki dan menentukan lokasi yang dianggap tepat untuk pelaksanaan Program Keluarga Harapan (PKH) sehingga implementasi program dapat lebih terarah dan tepat sasaran dan mampu mengurangi serta menanggulangi masalah kekumuhan di Kota Tebing Tinggi, provinsi Sumatera Utara

Pemodelan spasial telah berhasil mengidentifikasi lokasi yang tepat untuk pelaksanaan Program Keluarga Harapan(PKH) di Kota Tebing Tinggi. Pemodelan spasial memberikan saran lokasi yang tepat sasaran adalah kecamatan Bajenis dan Kecamatan Rambutan. Lokasi kurang tepat yaitu kecamatan Padang Hulu dan kecamatan Padang Hilir dan lokasi yang Tidak Tepat adalah Kecamatan Tebing Tinggi Kota.

Pemodelan spasial juga berhasil divalidasi dengan teknik trianggulasi dengan memanfaatkan bantuan foto satelit GoogleEarth dan foto lokasi kunjungan lapangan. Ini menjadikan model spasial yang di buat telah valid dan benar sehingga layak untuk dikonsumsi.

Pemanfaatan model spasial diharapkan mampu memberikan informasi kelayakan lokasi untuk PKH sehingga program ini lebih tepat sasaran dan mampu mengurangi kemiskinan yang pada akhirnya akan mengurangi kawasan pemukiman kumuh. 


\section{Saran}

Penelitian ini dilakukan dengan memakai lima indikator kemiskinan dari 16 indikator TNP2K. Penelitian selanjutnya diharapkan mampu menambahkan indikator lainnya sehingga analisis dan pemodelan spasial akan lebih tajam dan lebih objektif

\section{Daftar Pustaka}

[1] J. D. Putro, "Penataan Kawasan Kumuh Pinggiran Sungai Di Kecamatan Sungai Raya," J. Tek. Sipil, vol. 11, no. 1, 2011.

[2] Bahagia, I. Yunita, and Ruslin, "Analisa Kualitas Air Sumur Pemukiman Kumuh di Gampong Beurawe Kota Banda Aceh,” Serambi Eng., vol. 3, no. Khusus, pp. 285-291, 2018.

[3] H. Rizka, A. Purwoko, and Rujiman, "Perencanaan Penanganan Kawasan Pemukiman Kumuh Di Kelurahan Tanjung Tiram Kabupaten Batubara," Serambi Eng., vol. 3, no. Khusus, pp. 321-329, 2018.

[4] L. Andriana and A. Manaf, "Relevansi Aspek Kemiskinan dan Fisik Lingkungan Kumuh Pada Penentuan Lokasi Penerima Program KOTAKU (Studi Kasus Kecamatan Pamekasan Kabupaten Pamekasan)," J. Pengemb. Kota, vol. 5, no. 2, pp. 131-139, 2017, doi: 10.14710/jpk.5.2.131-139.

[5] K. Sosial, "Apa itu Program Keluarga Harapan," 2017. [Online]. Available: https://pkh.kemsos.go.id/?pg=tentangpkh-1. [Accessed: 25-Feb-2020].

[6] A. Ardiansyah, "Dampak Kemiskinan Kota Terhadap Perumahan dan Permukiman di Kota-Kota Besar di Indonesia," Artik. Bull. TERAS, 2009.

[7] D. J. C. Karya, "Permukiman Kumuh dan Upaya Penanganannya," 2016. [Online]. Available: http://ciptakarya.pu.go.id/bangkim/nusp-2/index.php?/berita/detail/permukiman-kumuh-danupaya-penanganannya. [Accessed: 25-Feb-2020].

[8] V. Anggara, "Analisis Tingkat Kekumuhan Dan Strategi Penanganan Kawasan Permukiman Kumuh Di Kecamatan Tanjung Beringin, Kabupaten Serdang Bedagai," Universitas Sumatera Utara, 2018.

[9] I. K. Thoriq, "Penanggulangan Kemiskinan Melalui Perencanaan Spasial Perkotaan," 2019. [Online].

Available: https://www.kompasiana.com/imaduddinkamalthoriq5443/5daf41650d8230240b6c4195/penanggu langan-kemiskinan-dalam-lingkup-spasial-perkotaan?page=all\#. [Accessed: 25-Feb-2020].

[10] Sugiyono, Metodologi Penelitian dan Pengembangan. Bandung. 2016.

[11] A. Dajan, Pengantar Metode Statistik Jilid II. 1986.

[12] TNP2K, "Indikator sosial, ekonomi dan Demografi status Kesejahteraan Penduduk Indonesia." [Online]. Available: http://bdt.tnp2k.go.id/sebaran/. [Accessed: 25-Feb-2020].

[13] D. H. U.N, R.Soelistijadi, and Sunardi, "Pemanfaatan Analisis Spasial untuk Pengolahan Data Spasial Sistem Informasi Geografi,” J. Teknol. Inf. Din., vol. X, pp. 108-116, 2005.

[14] J. M. Mustafa, Sirojuzilam, and N. Sulistiyono, "Analisis Tingkat Kerawanan Longsor Dengan Integrasi Analytical Hierarchy Process dan Pemodelan Spasial Sistem Informasi Geografis di Kabupaten Aceh Tenggara,” Serambi Eng., vol. 4, no. Khusus, pp. 471-481, 2019.

[15] M. A. M. Azaliatul Hidayah, Paharuddin, "Analisis Rawan Bencana Longsor Menggunakan Metode AHP (Analytical Hierarchy Process) Di Kabupaten Toraja Utara," Geocelebes, vol. 1, pp. $1-4,2017$.

[16] J. Harefa, Zulkifli, and A. S. Toha, "Analisis Daerah Rawan Bencana Tsunami Terhadap Pemanfaatan Lahan Perumahan dan Permukiman Kota Gunungsitoli Berbasis Geospasial," Serambi Eng., vol. 5, no. 1 Januari 2020, pp. 824-834, 2020.

[17] Samuel, "Apa Itu Validasi," 2011. [Online]. Available: http://samuel.blog.undip.ac.id/2011/03/22/apa-itu-validasi/. [Accessed: 26-Feb-2020].

[18] L. J. Moleong, Metodologi Penelitian Kualitatif, Revisi. Bandung: Remaja Rosdakarya, 2009.

[19] Badan Pusat Statistik (BPS), “Kota Tebing Tinggi Dalam Angka 2019,” 2019. 